\title{
PERFIL DOS SERVIÇOS DE INFORMAÇÃO DAS BIBLIOTECAS UNIVERSITÁRIAS DA GRANDE FLORIANÓPOLIS
}

\author{
Izabel Cunha \\ Graduada em Biblioteconomia UFSC \\ cunnha.izabel@gmail.com \\ Ana Clara Cândido \\ Doutora em Avaliação de Tecnologia \\ Professora no Departamento de Ciência da Informação - UFSC \\ acc.anaclara@gmail.com
}

\section{Resumo}

O objetivo do presente estudo foi identificar o perfil dos serviços de informação das bibliotecas universitárias da Grande Florianópolis. Foi realizado inicialmente um levantamento das instituições de ensino superior desta região. A coleta de dados sobre os serviços oferecidos por estas bibliotecas se deu através da aplicação de um questionário disponibilizado através da ferramenta Google Forms. Das 32 instituições de ensino superior identificadas, 24 são privadas e oito são públicas. A amostra deste estudo corresponde a 19 instituições respondentes. Dos resultados obtidos, é possível afirmar que entre os serviços considerados mais relevantes, estão: o empréstimo domiciliar; o empréstimo entre bibliotecas; a orientação ao usuário na recuperação de informações e a consulta na base de dados. No que diz respeito aos serviços voltados à comunidade, destacam-se as capacitações, as exposições e as palestras. Por fim, a partir da análise realizada é possível concluir que o perfil dos serviços de informação prestados pelas bibliotecas analisadas está, de maneira geral, diretamente pautado nas atividades que compõem a base da academia, ou seja, em apoiar as atividades de ensino, pesquisa e extensão traçadas pelas universidades.

Palavras-chave: Serviços de informação. Bibliotecas universitárias. Produtos de informação.

\section{INTRODUÇÃO}

A produção do conhecimento tem ocupado papel importante no atual contexto, tendo em vista a transição da sociedade na Era Industrial para a Sociedade da Informação e do Conhecimento. Essa importância se tornou ainda mais perceptível com o desenvolvimento da Ciência e da Tecnologia (C\&T). Neste contexto, os indivíduos têm buscado cada vez mais a educação continuada para o aprimoramento profissional, já que as empresas buscam profissionais capacitados e atualizados.

Diante deste cenário, as instituições de ensino tornam-se cruciais na formação dos indivíduos. Estudos demonstram a importante função das instituições de ensino superior (IES) no avanço regional, tanto no que diz respeito ao processo de formação de indivíduos mais educados quanto na produção de conhecimento científico e inovações. As IES são agentes locais importantes para o progresso de uma região (CHIARINI; VIEIRA; ZORZIN, 2012). Para reforçar a sua importância diante deste cenário, as unidades de informação podem assumir um papel de destaque.

Neste âmbito, as bibliotecas universitárias desempenham uma função fundamental no acesso e disponibilização da informação e, assim como qualquer tipo de biblioteca, deve atender de modo eficiente e eficaz seus usuários. Para cumprir este papel necessitam dispor, no mínimo, de um ambiente organizado, um acervo variado e serviços de informação que agreguem valor para seus 
usuários finais. Esses elementos colaboram com o objetivo da biblioteca universitária que é dar suporte para o ensino, pesquisa e extensão da instituição de ensino na qual está inserida.

$\mathrm{O}$ atendimento da demanda de sua comunidade usuária é o que justifica a existência de qualquer unidade de informação. No entanto, para que isso ocorra, a biblioteca deve dispor de uma gama de serviços que consiga responder às mais variadas necessidades informacionais. Desta forma, os serviços de informação prestados nas bibliotecas universitárias, assim como seu acervo, devem dar ênfase na formação e satisfação de seus usuários.

A satisfação com os serviços oferecidos é essencial para qualquer instituição prestadora de serviços, pois, permite atrair novos clientes/usuários e possibilita a fidelização de clientes/usuários antigos. Para isso, se faz necessário recursos humanos qualificados para a mediação da informação, na busca de fontes relevantes, bem como possibilitem o acesso à informação.

A temática debatida no presente estudo apresenta-se atual e relevante pela característica de intangibilidade dos serviços e unidade de negócio das unidades de informação. Esta característica representa um desafio sobre a percepção dos gestores na decisão sobre os serviços que podem satisfazer as necessidades informacionais dos usuários, bem como atrair os usuários potenciais. A identificação do perfil dos serviços prestados pode auxiliar os gestores na adoção de diferentes serviços para garantir a satisfação da comunidade usuária. Frente a este desafio, a pergunta que este estudo busca responder é: Qual o perfil dos serviços de informação prestados pelas bibliotecas universitárias da região da Grande Florianópolis?

$O$ presente estudo pretende analisar o perfil atual da oferta de serviços prestados pelas bibliotecas universitárias, pois entende-se que este fator pode contribuir para que os gestores conheçam quais os serviços mais frequentes oferecidos pelas unidades de informação nesta região. Justifica-se a relevância de conhecer o perfil da oferta dos serviços de informação, conforme a perspectiva do bibliotecário, como aliado na tomada de decisão dos gestores de unidades de informação. E desta forma, com possibilidade de criação de novos serviços que atendam com maior prontidão às demandas que atualmente não são atendidas e/ou propor serviços com alto grau de novidade. Espera-se que consequentemente possam satisfazer uma maior gama de usuários potenciais e fortalecer relações com usuários já estabelecidos.

Além disto, os resultados desta pesquisa poderão contribuir para verificação do perfil, padrões e especificidades dos serviços de informação em bibliotecas que poderá encorajar a oferta de novos serviços, bem como uma análise mais aprofundada que permita verificar causas e aspectos culturais neste âmbito.

Por fim, uma justificativa adicional e relevante se dá pela observação, ao longo das pesquisas em base de dados da área de Ciência da Informação, a ausência de estudos sobre o perfil dos serviços de informação no âmbito das bibliotecas. Sendo esta, uma lacuna identificada na literatura com potencialidades de futuros estudos empíricos.

Sendo assim, o objetivo geral da pesquisa consiste em identificar o perfil dos serviços de informação das bibliotecas universitárias da região da Grande Florianópolis.

\section{OFERTA DE SERVIÇOS PELAS BIBLIOTECAS: DO DESENVOLVIMENTO TECNOLÓGICO AO ATENDIMENTO DE NOVAS DEMANDAS}

A sociedade tem passado por períodos que propiciam diversos progressos científicos e tecnológicos. Entre os avanços ocorridos, destaca-se o desenvolvimento das tecnologias da informação e comunicação (TICs), gerando grandes impactos nas formas de criação, compartilhamento de informações e novas formas de relações sociais. Este acelerado desenvolvimento tecnológico causa profundas transformações nos mais variados setores da sociedade (MACHADO, 2013).

A introdução destas novas tecnologias mudou não somente a fabricação de produtos e fazeres técnicos, mas também o mercado. Este passou a perceber a necessidade de se adequar para atender melhor seus clientes/ usuários. Essa realidade não se restringiu somente aos setores industriais, mas igualmente ocorreu em diversas áreas. No caso das bibliotecas universitárias, instrumento deste estudo, a realidade não foi diferente. $\mathrm{O}$ uso de novas tecnologias é cada vez maior e as bibliotecas 
universitárias buscam a modernização para oferecer aos seus usuários sistemas automatizados eficientes. Isto permite $o$ acesso à informação via Web, tornando este centro de informação sem fronteiras (POTY et al, 2011).

A expansão de novas tecnologias criou desafios às bibliotecas, principalmente, no que diz respeito à criação de novos serviços de informação. No entanto, ao contrário do que imaginavam estas transformações não significaram o desaparecimento das bibliotecas. Essas mudanças resultaram em um perfil de Unidades de Informação mais conectadas e modernizadas. Bueno e Messias (2013, p. 2) reconhecem que:

[...] a inserção das tecnologias da informação e comunicação na rotina de bibliotecas e centros de informação além de otimizar processos, instituiu uma nova dinâmica na produção, organização e distribuição de produtos e serviços informacionais.

Para Campos (2007) a tecnologia não é uma condição obrigatória, mas exerce um papel importante para que a biblioteca se mantenha atualizada em relação às necessidades informacionais de seus usuários, gerando assim, novos serviços e novas formas de intercâmbio. $\mathrm{O}$ autor ainda acrescenta que "a ênfase está no usuário, e a tecnologia é um instrumento considerado essencial para viabilizar essa perspectiva" (CAMPOS, 2007, p. 8).

Neste novo cenário, a informação exerce um papel estratégico e a biblioteca compete com formas mais cômodas de busca e acesso à informação. Para atender novas demandas e adaptar-se à atual realidade as bibliotecas universitárias passam a incorporar as TICs ao acervo, e assim, os usuários começam a usufruir de serviços mais eficientes, precisos e individualizados. A Unidade de Informação que antes atuava de forma passiva se torna uma instituição mais ativa e comprometida.

Para Machado (2013), esse desenvolvimento acelerado possibilitou a criação de serviços paralelos e alternativos aos das bibliotecas tradicionais, deste modo há maior interatividade e adequação dos serviços aos usuários. $\mathrm{O}$ acesso aos recursos informacionais proporcionou não só a criação de novos serviços como permitiram ao profissional da informação processar com agilidade uma grande massa informacional, substituindo os processos manuais.
No entanto, Bueno e Messias (2013, p. 2) afirmam que "a amplitude de acesso aos recursos de informação não transformou apenas o mercado da informação como também o perfil do usuário, atualmente muito mais crítico e exigente". Para os autores, as redes telemáticas têm sido cruciais para as Unidades de Informação, especialmente as bibliotecas, pois é por meio delas que as novas demandas de serviços informacionais podem ser supridas.

Os novos serviços variam de serviços simples como catálogos eletrônicos que facilitam a busca dos materiais de forma remota, softwares de gerenciamento de acervos que mantém comunicação direta com os usuários, serviços de referência digital até sofisticados cursos de busca, recuperação e representação de informações em áreas específicas do conhecimento humano (CAREGNATO, 2000). Uma infinidade de novos serviços criados que não restringem mais a biblioteca e o usuário ao acesso físico fazem com que essa instituição passe a ocupar espaços além das paredes.

\subsection{SERVIÇOS DE INFORMAÇÃO}

A literatura específica sobre o assunto, conforme Rozados (2006) e Trzeciak (2009), não aponta um conceito de serviços de informação. Apenas são encontradas manifestações sobre sua caracterização e funções. Uma possível explicação para isso se deve pelo fato que a palavra serviço, por si só, é particularmente ambígua (ROZADOS, 2006).

De acordo com Trzeciak (2009) há diversas designações para o termo serviços de informação, dentre eles: serviços de referência, serviços de informação tecnológica, serviços de informação bibliográfica, etc. A definição destes serviços também está relacionada à sua função.

Em documento denominado "Diretrizes para a Avaliação de Sistemas e Serviços de Informação" desenvolvido por Lancaster em 1978, sob contrato com a Unesco, a função principal do serviço de informação é dita como: "servir de encalce entre uma porção particular de usuários e o universo dos recursos de informação em forma impressa e não impressa" (LANCASTER, 1978, p. 6, tradução nossa). O mesmo documento menciona os papéis passivo e ativo destes 
serviços. No papel passivo: a função do serviço de informação é proporcionar que qualquer informação requerida por um usuário esteja disponível, sempre que possível, no momento em que for solicitada. No papel ativo: a função do serviço de informação é alertar os usuários sobre os documentos que possam ser de seu interesse.

Segundo Foskett (1969), o serviço de informação se desenvolveu, inicialmente, no campo das pesquisas científicas e industriais, até chegar à forma característica atual. Foi neste campo que surgiu a ideia de atribuir a uma pessoa, a responsabilidade de organização do acervo de informações recém publicadas que seriam úteis aos próprios pesquisadores.

Campello (1998, p. 2) afirma que os serviços de informação destinados à comunidade "surgiram nos Estados Unidos e na Grã Bretanha na década de 60, influenciados pelo Manifesto da UNESCO para as Bibliotecas Públicas". Na visão de Trzeciak (2009) um serviço pode ser tanto a venda feita para um usuário como, por exemplo, a realização de fotocópias ou traduções. Da mesma forma, tanto quanto a finalidade de um produto informacional, como um boletim de alerta.

No que se refere às características dos serviços de informação, estes partilham algumas características com outras classes de serviços. Entre elas, Dholakia, Mundorf e Dholakia (1997) destacam:

a) Intangibilidade: os serviços de informação são essencialmente intangíveis. No entanto, para movimentar e processar as informações, são necessários equipamentos;

b) Volatilidade: depois de serem realizados, grande parte dos serviços de informação não deixam rastros físicos;

c) Uso intensivo de tecnologia: grande parte dos serviços de informação faz uso intensivo de diversas tecnologias;

d) Prestação de serviços interorganizacionais: serviços de informação são quase sempre oferecidos por complexas e longas cadeias de organizações associadas.

Além disso, estes mesmos autores relatam que os serviços de informação possuem algumas características de natureza singular, tais como:

a) Serviço em rede: os serviços de informação precisam de uma rede para atingir os usuários normalmente, que podem ser públicas ou privadas, análogas ou digitais, comutadas ou de via física, com ou sem fio, estreitas ou amplas, em termos de amplitude de faixas (capacidade de transmitir informações);

b) Interatividade: muitos serviços de informação oferecem interatividade entre os usuários ou entre os usuários e bancos de informação;

c) Caráter externo da rede: os serviços em rede e a interatividade criam determinados tipos de exterioridade exclusivas dos serviços de informação. Estas exterioridades podem ser negativas e positivas, onde outras partes, aquelas que não adotaram o serviço, usufruem de vantagens ou experimentam desvantagens. Logo, esse caráter externo da rede pode se transformar em obstáculo ou facilitador da difusão de serviços de informação.

A análise realizada por Rozados (2006, p. 54), reconhece que "Se uma das funções das unidades de informação é informar, o principal objetivo do serviço de informação é conseguir que todas as informações solicitadas sejam satisfeitas".

Os serviços de informação, além de ferramentas para a disseminação da informação são também considerados resultado do processo de gestão da informação, pois tratam das necessidades e do uso que o usuário faz da informação, bem como dos materiais disponíveis para o acesso à informação (BORGES, 2007).

Os serviços prestados variam de acordo com os usuários, e embora existam serviços considerados imprescindíveis cada instituição deve atender às peculiaridades do local no qual está inserida. Conhecer as necessidades dos usuários e traçar um perfil, faz-se necessário para a criação de novos serviços de informação. Desta forma, a biblioteca adequase melhor às demandas e a realidade de seus usuários.

\subsection{TIPOS DE SERVIÇOS DE INFORMAÇÃO}

Quanto à tipologia de serviços de informação, Borges (2007) divide os serviços em dois grupos: os serviços de atendimento à demanda e os serviços de antecipação à demanda.

Os serviços de atendimento à demanda são desenvolvidos sob encomenda para atender a demandas específicas dos usuários, por 
exemplo, os levantamentos bibliográficos, entre outros.

Já os serviços de antecipação à demanda visam atender às necessidades informacionais dos usuários, antes mesmo delas se tornarem explícitas, por exemplo, os serviços de disseminação seletiva da informação e os alertas bibliográficos.

Os serviços de informação são diferenciados em cada tipo de biblioteca, pois, são criados para satisfazer determinado grupo de usuários e suas necessidades informacionais. Os principais serviços prestados nas bibliotecas universitárias, segundo Amboni (2002, p. 173) são:

a) Sumários e alerta;

b) Empréstimo domiciliar;

c) Empréstimo entre bibliotecas;

d) Disseminação da informação;

e) Orientação ao usuário na recuperação de informações;

f) Comutação bibliográfica;

g) Consulta a base de dados;

h) Treinamento de usuários;

i) Reprografia;

j) Normalização de trabalhos técnicocientífico de acordo com a ABNT;

k) Visita orientada;

l) Novas aquisições;

m) Catalogação na fonte;

n) Mercado editorial.

A tecnologia de informação progrediu ao longo de algumas dimensões fundamentais. Uma vez que os serviços de informação são criados e prestados mediante a aplicação da informática, a evolução desses serviços é afetada pela forma em que se progride e transforma essas tecnologias (DHOLAKIA; MUNDORF; DHOLAKIA, 1997).

Os serviços de informação e as bibliotecas, neste novo contexto, passam a obter uma dimensão muito mais vasta, sendo que, com a disponibilização cada vez maior de recursos informacionais disponíveis pela web, as informações de interesse de seus usuários não se limitam somente aos recursos internos da biblioteca, mas também, e de forma progressiva aos recursos externos, disponíveis pela web (MARCONDES; MENDONÇA; CARVALHO, 2006).

Para atender essas novas demandas, as bibliotecas sentiram a necessidade de adaptar os serviços de informação prestados, de forma que possam oferecer alternativas dos seus serviços tradicionais de forma on-line. Dentre esses novos serviços informacionais oferecidos Carvalho e Lucas (2004) destacam:

a) Provisão de documentos on-line: Podem ser realizados, utilizando meios eletrônicos ou virtuais. Ressalta algumas: a pesquisa on-line do acervo da biblioteca, comutação bibliográfica on-line, fornecimento de cópias on-line, empréstimo entre bibliotecas por meio de formulários on-line e etc.;

b) Provisão de auxílio bibliográfico, por meio de: Atendimento em questões de referência simples e complexas, localização de materiais em variadas fontes e suportes eletrônicos e levantamento bibliográfico em assuntos especializados;

c) Serviço de alerta eletrônico: Podem ser formais, como, listas de aquisições on-line, lista de duplicatas, formulário on-line para solicitação de novas aquisições e formulário on-line para solicitação de duplicatas. E também podem ser informais como a divulgação de novos produtos e serviços oferecidos pela biblioteca, divulgação de promoções e cursos oferecidos, por meio de boletins informativos on-line e alertas eletrônicos no site da biblioteca;

d) Orientação ao usuário: Orientação e normalização bibliográfica via Web por meio de tutoriais e manuais explicativos. Vocabulário controlado disponibilizando em forma virtual por meio de documento de texto, também oferecer índice de assuntos para a padronização de terminologia técnica utilizada na biblioteca, para agilizar a recuperação da informação por parte do usuário.

Percebe-se desta forma, que a Web mudou radicalmente os serviços de informação prestados pelas bibliotecas. Marcondes, Mendonça e Carvalho (2006, p. 175) afirmam que este novo contexto:

[...] proporciona um ambiente informacional amplo, global, de alcance nunca visto pelos antigos serviços bibliotecários, acostumados a trabalhar num ambiente delimitado, com uma comunidade de usuários identificável, restrita e até mesmo, conhecida pessoalmente (MARCONDES; MENDONÇA;

CARVALHO, 2006, p.175).

Assim, as bibliotecas universitárias passam a contar com a oportunidade de introduzir em seus sites um aglomerado de recursos prestados pela $W e b$ que sejam de interesse de 
seus usuários. Os usuários que antes limitavam-se aos serviços prestados fisicamente, podem ter acesso aos diferentes recursos e tipos de serviços de informação, independentemente de sua localização física.

$\mathrm{O}$ ambiente de trabalho das bibliotecas mudou significativamente, a Internet e as TICs trouxeram situações diferentes na gestão de serviços e recursos nas bibliotecas. Por sua vez, as Unidade de Informação também necessitam de constante adaptação às realidades atuais.

Novos tipos de serviços de informação são demandados constantemente por sua comunidade de usuários e com isso, os gestores devem ficar atentos. Deve-se salientar que esses serviços dependem também de constantes avaliações e divulgações para a comunidade usuária.

\section{PROCEDIMENTOS METODOLÓGICOS}

A pesquisa do ponto de vista dos objetivos é classificada como descritiva pois "[...] não há a interferência do pesquisador, isto é, ele descreve o objeto de pesquisa" (SEVERINO, 2002, p. 70). Esta pesquisa pode ser assim caracterizada pelo fato de buscar o conhecimento do perfil dos serviços de informação para uma população delimitada (bibliotecas universitárias da Grande Florianópolis).

Quanto à forma de abordagem do problema, é quantitativa, pois "está relacionada à quantificação de dados obtidos mediante a pesquisa" (SOARES, 2003, p. 17). Para utilizá-la, requer o emprego de recursos e técnicas estatísticas, possibilitando descobrir e classificar a relação entre variáveis. Também pode ser considerada qualitativa, uma vez que a interpretação dos dados e a atribuição de significados são feitas indutivamente pelo pesquisador (MENEZES, 2009).

$\mathrm{O}$ universo da pesquisa abrange as bibliotecas universitárias da região da Grande Florianópolis, que engloba os municípios de: Águas Mornas, Alfredo Wagner, Angelina, Anitápolis, Antônio Carlos, Biguaçu, Canelinha, Florianópolis, Governador Celso Ramos, Leoberto Leal, Major Gercino, Nova Trento, Palhoça, Paulo Lopes, Rancho Queimado, Santo Amaro da Imperatriz, São Bonifácio, São João Batista, São José, São Pedro de Alcântara e Tijucas.
Ao realizar o levantamento de dados para identificar todas as instituições de ensino superior (IES) públicas e privadas, definiu-se como critérios: Pesquisar somente universidades na modalidade de ensino presencial e instituições de ensino com caráter multidisciplinar, pois unidades que atendem uma só área do conhecimento podem oferecer poucos ou nenhum. Com o ensino presencial, os serviços informacionais tornam-se mais abrangentes.

A relação das bibliotecas foi obtida por meio da plataforma do Ministério da Educação e Cultura (MEC), disponível em: <http://emec.mec.gov.br>, que inclui todas as universidades cadastradas oficialmente no País, de forma legal. A plataforma permite a consulta por meio de Para obter as planilhas das IES dos municípios da Grande Florianópolis, utilizou-se a Consulta Textual.

A plataforma contém o nome da instituição, local de oferta, endereço, CEP, município e Unidade Federativa (UF). Para visualizar as planilhas, seleciona-se a opção município e busca-se o desejado para saber quais são suas IES cadastradas. Somente para o município de São João Batista que foi necessário selecionar dentro da planilha as unidades pertencentes a Santa Catarina.

Para filtrar as instituições públicas das privadas, foi utilizada a busca interativa, selecionando o Estado, posteriormente o município e, por fim, desabilitando a opção "Distância". Para sanar qualquer dúvida, foi consultado o site da unidade. A coleta realizada no dia 15 de maio de 2017 obteve uma amostra de 32 instituições de ensino superior, sendo 24 privadas e oito públicas.

\subsection{INSTRUMENTO DE COLETA DE DADOS}

Como instrumento de coleta de dados, foi utilizado um questionário construído especificamente para este estudo com o objetivo de identificar os serviços prestados pelas bibliotecas universitárias. $\mathrm{O}$ questionário, desenvolvido por meio do Google Forms, foi composto de três partes. A primeira parte foi destinada para a classificação do nível de relevância dos serviços de informação prestados pela biblioteca, conforme sua opinião. A segunda parte foi designada com o mesmo propósito da primeira, só que os serviços são voltados à 
comunidade. E a terceira para a caracterização dos respondentes, que nesta pesquisa, foram os bibliotecários. Ou seja, qual a sua formação, cargo/função e tempo que a exerce. $\mathrm{O}$ referencial teórico para a construção do questionário pode ser observado no Quadro 1.

Quadro 1: Referencial teórico para a elaboração do questionário

\begin{tabular}{|c|c|}
\hline Autor(es) & Conteúdo \\
\hline Amboni (2002); Cabreira (2011); Carvalho e \\
Lucas (2004); Merlo Vega (2000); Rozados \\
(2006)
\end{tabular}

Fonte: Elaborado pela autora (2017).

Após a fase de pré-teste que ocorreu no mês de junho e as adaptações necessárias, o questionário foi enviado por e-mail para as bibliotecas que compõem o corpus da pesquisa, entre os meses de julho e agosto de 2017. A abordagem foi realizada por meio de e-mail institucional.

\subsection{DO OBJETO DE ANÁLISE: AS BIBLIOTECAS UNIVERSITÁRIAS}

A biblioteca universitária é uma unidade de informação mantida por uma Instituição de Ensino Superior (IES) que atende às necessidades informacionais dos alunos, professores, funcionários e comunidade, fornecendo apoio às atividades de ensino, pesquisa e extensão. Pode ser uma única biblioteca ou várias organizadas como sistema ou rede. (CUNHA; CAVALCANTI, 2008).

Sousa e Fujino (2009) afirmam que as bibliotecas universitárias devem seguir as diretrizes administrativas e políticas da IES à qual é subordinada, tendo em função dessa contingência uma autonomia limitada. Contudo as novas realidades que se apresentam com as tecnologias, ambientes virtuais, educação à distância, repositórios informacionais, direitos autorais entre outros; resulta no surgimento de novas demandas de produtos e serviços e é necessário que a sua autonomia seja repensada.

De acordo com Morigi e Pavan (2004, p. 122), essas Unidades de Informação "[...] são responsáveis pelo tratamento, armazenamento e disponibilização do acervo das mesmas e devem estar de acordo com os objetivos de suas instituições mantenedoras". Essas instituições são localizadas principalmente nas universidades e centros de produção técnicocientífica.

\section{RESULTADOS}

A seguir são descritas as respostas obtidas por meio do questionário, das bibliotecas universitárias da região da Grande Florianópolis. Entre as 32 bibliotecas que compõem o universo estudado, 19 responderam, sendo 13 privadas e seis públicas.

$\mathrm{Na}$ primeira parte do questionário, foi solicitado aos bibliotecários para que atribuíssem o nível de relevância para cada um dos serviços da listagem, apresentados no Gráfico 1. Caso o serviço não seja prestado, eles deveriam assinalar a alternativa correspondente.

Gráfico 1: Nível de relevância atribuídos pelos respondentes aos serviços de informação prestados 


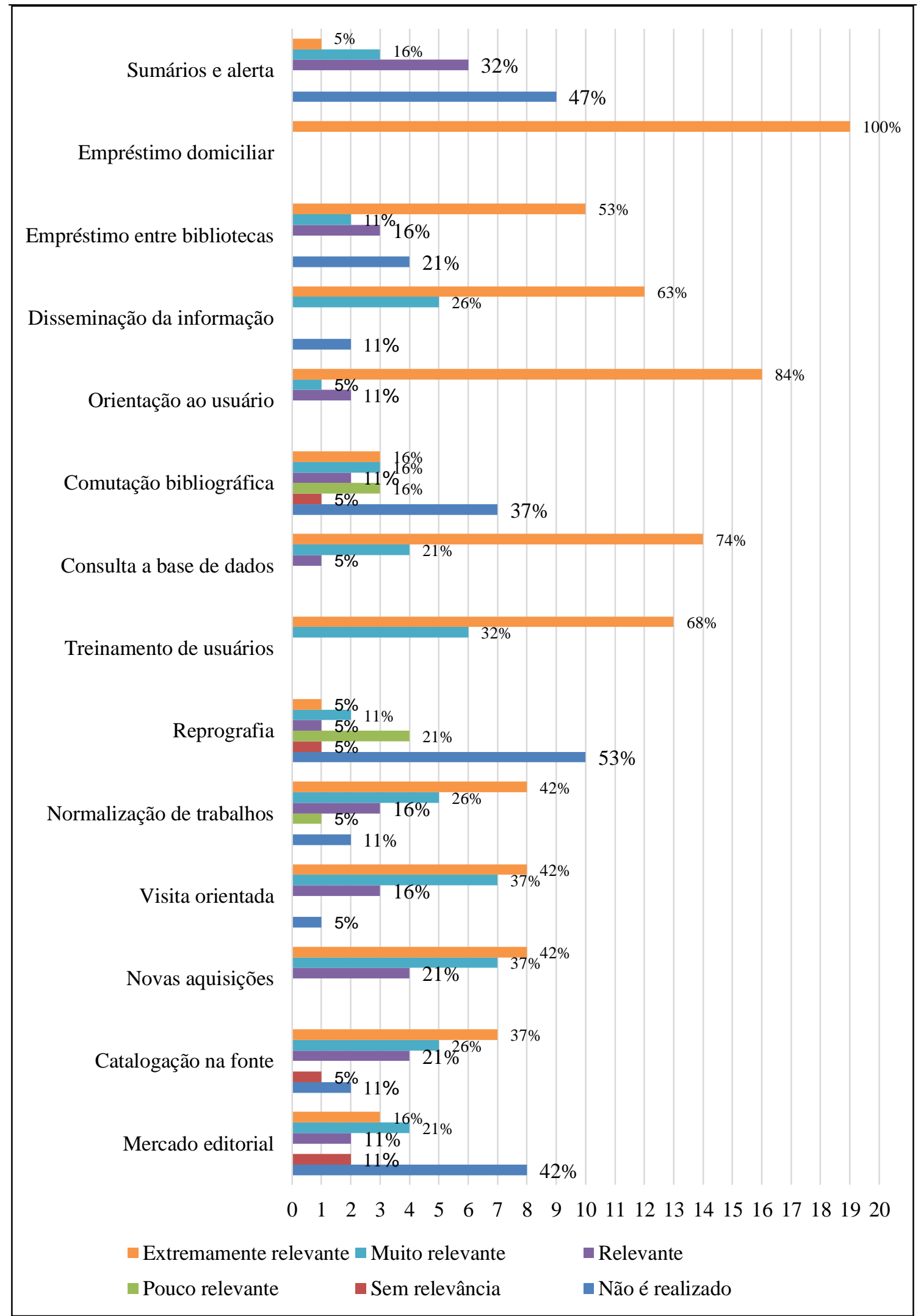

Fonte: Dados da pesquisa (2017).

Entre os serviços de informação listados, o empréstimo domiciliar é o único considerado por $100 \%$ dos bibliotecários como extremamente relevante. Outros serviços apontados como de extrema relevância são a orientação ao usuário na recuperação de 
informações com $84 \%$ (16) e consulta a base de dados com $74 \%$ (14).

Os serviços informacionais considerados por maioria dos bibliotecários como muito relevante são a visita orientada e novas aquisições com 37\% (7) dos respondentes, seguido do treinamento de usuários com $32 \%$ (6). Serviços como disseminação da informação, normalização de trabalhos técnico-científico de acordo com a Associação Brasileira de Normas Técnicas (ABNT) e catalogação na fonte obtiveram $26 \%$ (5).

Entre os serviços considerados relevantes, destacam-se os sumários de alerta, considerado relevante por $32 \%$ (6) dos bibliotecários, e, novas aquisições e catalogação na fonte por $21 \%$ (4). A mesma porcentagem de bibliotecários, $21 \%$ (4), consideram a reprografia como um serviço pouco relevante.

Apenas quatro dos serviços elencados são apontados como sem relevância, sendo o mercado editorial o único serviço considerado irrelevante por $11 \%$ (2) dos bibliotecários. Comutação bibliográfica, reprografia e catalogação na fonte são os outros serviços considerados por $5 \%$ (1) como irrelevantes.

Dos serviços listados, reprografia é o menos prestado pelas bibliotecas, com 53\% (10), seguido de sumários de alerta com $47 \%$ (9) e mercado editorial com $42 \%$ (8).

Foi solicitado para que os bibliotecários mencionassem outros serviços que não foram elencados, caso achassem pertinente, e seu respectivo nível de relevância. Entre os serviços mencionados pelos bibliotecários, destacam-se: acesso wireless para visitantes; espaço de inclusão digital; repositório institucional; serviço de acessibilidade informacional; portal de periódicos; reservas e renovação on-line; salas de estudo individuais e disponibilidade de base de dados. O nível de relevância atribuído aos serviços fica entre extremamente relevante e muito relevante.

Também foi destinado um espaço para que os bibliotecários apontassem quais dos serviços listados são utilizados com maior frequência pelos usuários da biblioteca. Dentre eles, o empréstimo domiciliar é apontado por $74 \%$ (14) dos bibliotecários como sendo o mais utilizado. Isso pode ser justificado pelo fato de ser considerado por unanimidade dos bibliotecários como um serviço extremamente relevante. Outros serviços destacados foram a orientação ao usuário na recuperação de informações com indicação de $42 \%$ (8) dos bibliotecários e treinamento com $16 \%$ (3).

Entre os serviços da biblioteca mencionados, o empréstimo domiciliar é caracterizado por maior parte dos bibliotecários, com 37\% (7) dos respondentes, como serviço de excelência; seguido de disseminação da informação com $26 \%$ (5). Orientação a recuperação da informação e atendimento também são apontados como serviço de excelência por $21 \%$ (4) dos bibliotecários e treinamento do usuário por $16 \%$ (3).

$\mathrm{Na}$ segunda parte do questionário, assim como a primeira, foi solicitado que os bibliotecários atribuíssem o nível de relevância aos serviços expostos. Desta vez, os serviços informacionais eram voltados à comunidade, de acordo com a Gráfico 2. 


\section{Relatos de Pesquisa}

Gráfico 2: Nível de relevância atribuídos pelos respondentes aos serviços de informação voltados à comunidade

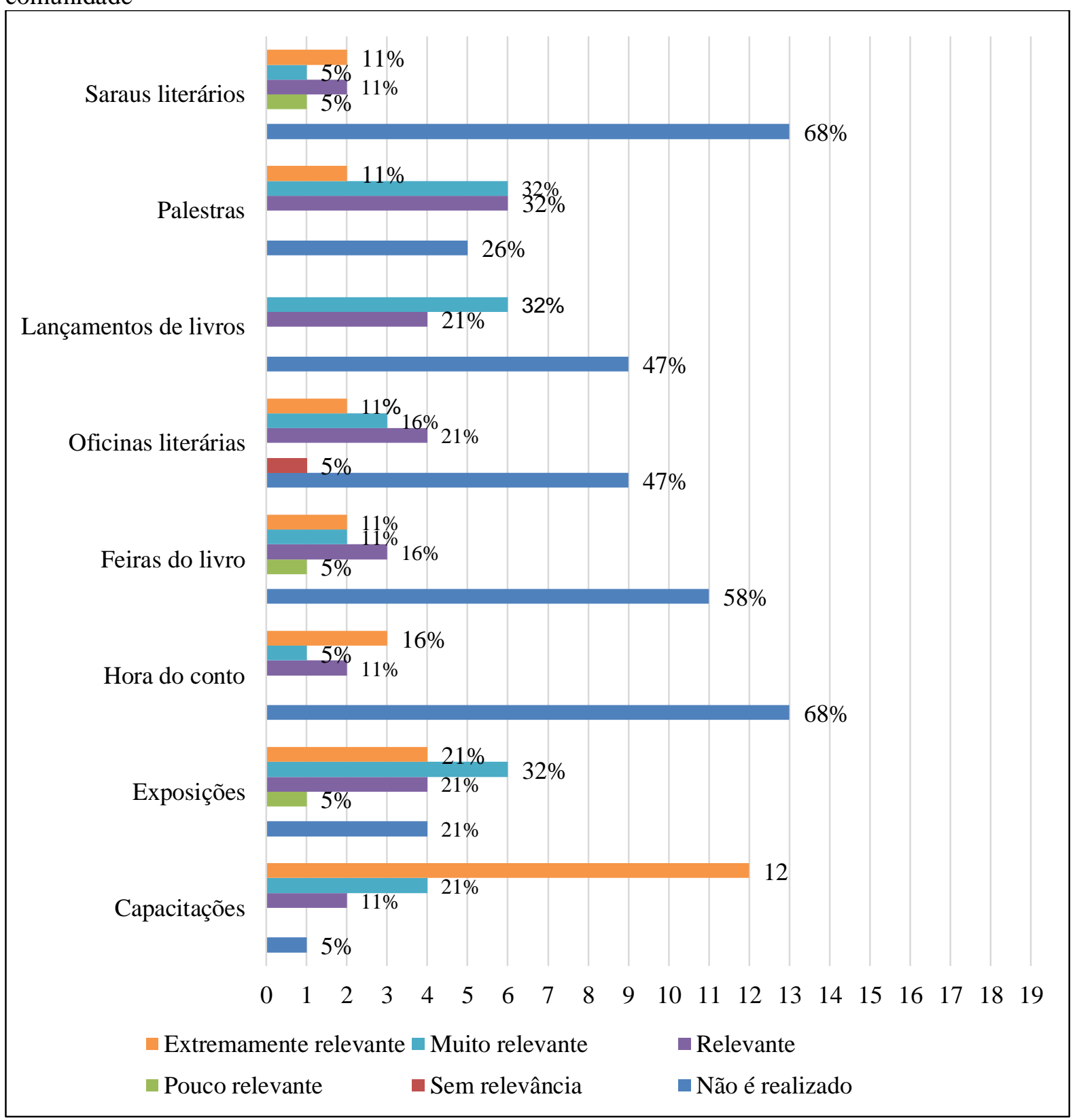

Fonte: Dados da pesquisa (2017).

Entre os serviços voltados à comunidade que são considerados extremamente relevantes por maior parte dos bibliotecários, destaca-se as capacitações com $63 \%$ (12), seguido de exposições com $21 \%$ (4) e hora do conto com $16 \%(3)$.

Os serviços que mais são apontados como muito relevantes são as palestras, lançamentos de livros e exposições, classificados por $32 \%$ (6) dos bibliotecários. A mesma porcentagem também considera as palestras como relevante. Saraus literários, feiras de livro e exposições são apontados como pouco relevante por apenas 5\% (1) dos bibliotecários. Oficinas literárias é o único serviço apontado como sem relevância por $5 \%$ (1) dos respondentes também.

Entre os serviços que não são realizados, $68 \%$ (13) indicam os saraus literários e hora do conto, $58 \%$ (11) apontam as feiras do livro e $47 \%$ (9) os lançamentos de livro e oficinas literárias. Outros serviços elencados pelos bibliotecários que não estavam listados foram o café literário e participação de projetos de extensão como oficinas de xadrez e origami. Dos serviços listados os utilizados com mais 
frequência pelos usuários da biblioteca são as capacitações, apontados por $42 \%$ (8) dos bibliotecários e as exposições apontadas por $16 \%$ (3). Dentre esses serviços, 32\% (6) dos bibliotecários caracterizam as capacitações como serviço de excelência e 11\% (2) apontam as oficinas.

\section{CONSIDERAÇÕES FINAIS}

As unidades de informação são instituições voltadas para a coleta, tratamento, armazenamento e disseminação da informação. Sua existência justifica-se, somente quando essa informação é utilizada pelas pessoas, seja para os mais diversos fins como o trabalho, a pesquisa e o lazer.

$\mathrm{O}$ fato dos serviços serem intangíveis dificulta a percepção da qualidade pelo cliente antes de seu consumo. Atentar-se aos serviços prestados pela biblioteca é uma forma de buscar a melhoria contínua da unidade de informação, pois dessa forma é possível verificar o que está bom e o que pode melhorar, ou ainda que serviço pode ser criado para atender novas demandas.

A percepção dos bibliotecários em relação ao nível de relevância dos serviços de informação prestados pela biblioteca onde atua pode auxiliar no estabelecimento de ações e tomada de decisões. Por exemplo, a relevância atribuída ao empréstimo domiciliar por todos os bibliotecários da amostra ressalta a importância da biblioteca investir em vários exemplares de obras que são emprestadas com maior frequência.

Outros serviços como capacitações, orientação aos usuários na recuperação da informação, consulta a base de dados, que foram atribuídos níveis de relevância significativo evidencia a necessidade de investimento na qualificação de seus funcionários e numa infraestrutura que possa atender a demanda de seus usuários, pois um bom atendimento garantirá a sua satisfação. A satisfação possibilitará que os usuários voltem a usufruir dos serviços oferecidos.

Serviços caracterizados como pouco relevantes ou sem relevância como sumários de alerta, comutação bibliográfica, saraus literários, feiras de livro, exposições e oficinas literárias podem ter sido determinados assim por causa do pouco uso ou falta dele. A falta de uso pode refletir na falta de divulgação destes serviços ou o desinteresse por parte da comunidade usuária. Os gestores devem estudar com cautela a causa dessa caracterização para tomar a melhor decisão cabível em relação ao serviço, podendo resultar em uma maior divulgação ou na exclusão do mesmo.

Observa-se que os serviços considerados mais relevantes como empréstimo domiciliar, empréstimo entre bibliotecas, orientação ao usuário na recuperação de informações e consulta a base de dados, são prestados por todas as bibliotecas. Com base nisso, é possível concluir que o perfil dos serviços de informação prestados pelas bibliotecas universitárias da região da Grande Florianópolis está intrinsecamente ligado ao cerne da biblioteca universitária, apoiar as atividades de ensino, pesquisa e extensão.

Recomenda-se que cada instituição realize iniciativas para verificar demandas novas que podem ser através de métodos tradicionais, como é o caso dos estudos de usuários ou mecanismos informais, como as redes sociais. A aproximação com os usuários e potenciais usuários é imprescindível, pois permite conhecer o perfil e as necessidades dos usuários. Além de permitir a mensuração do nível de satisfação com relação aos serviços oferecidos, auxiliando na melhoria dos serviços existentes. Como consequência potencial, ressalta-se a criação de novos serviços coerentes com realidades atuais para suprir a todas as necessidades dos usuários.

\section{INFORMATION SERVICES PROFILE OF THE UNIVERSITY LIBRARIES IN FLORIANOPOLIS}

\section{Abstract}

This study aims to identify the profile of the information services of the university libraries of Florianopolis region. A survey of the higher education institutions of this region was carried out initially. The collection of data on the services offered by these libraries was done through the application of a questionnaire made available of the Google Forms tool. Of the 32 higher education institutions identified, of which 24 are private and eight are public, the 
sample of this study corresponds to 19 respondent institutions. Among the results obtained, it is possible to affirm that among the services considered more relevant, are: the home loan; interlibrary loan; the user orientation in retrieving information and the query in the database. With regard to services aimed at the community, we highlight the capacities, the exhibitions and the lectures. Finally, based on the analysis carried out, it is possible to conclude that the profile of the information services provided by the analyzed libraries is, in general, directly based on the activities that make up the foundation of the academy. In other words, to support the teaching, research and extension activities traced by universities.

Keywords: Information services. University libraries. Information products.

\section{REFERÊNCIAS}

AMBONI, Narcisa de Fátima. Qualidade em serviços: dimensões para orientação e avaliação das bibliotecas universitárias federais brasileiras. 2002. $227 \mathrm{f}$. Tese (Doutorado em Engenharia de Produção) Universidade Federal de Santa Catarina, Florianópolis. 2002. Disponível em: $<$ http://www.tede.ufsc.br/teses/PEPS2632.pdf >. Acesso em: 9 jun. 2017.

BORGES, Mônica Erichsen Nassif. O essencial para a gestão de serviços e produtos de informação. Revista Digital de Biblioteconomia e Ciência da Informação, Campinas, v.5, n. 1, p. 115-128, jul./dez. 2007. Disponível em:

<http://dx.doi.org/10.20396/rdbci.v5i1.2007> . Acesso em: 3 jun. 2017.

BRASIL. Ministério da Educação e Cultura. e-MEC. [Brasília], 2017. Disponível em: <http://emec.mec.gov.br/>. Acesso em: 20 abr. 2017.

BUENO, Aparecida de Fátima Cavalheiro; MESSIAS, Lucilene Cordeiro da Silva. As novas tecnologias e os impactos nas bibliotecas: habilidades do profissional bibliotecário na atualidade. In: In: CONGRESSO BRASILEIRO DE BIBLIOTECONOMIA, DOCUMENTAÇÃO E CIÊNCIA DA INFORMAÇÃO, 25., 2013, Florianópolis. Anais eletrônicos...

Florianópolis: FEBAB, 2013. Disponível em: $<$ https://portal.febab.org.br/anais/article/view/ 1284>. Acesso em: 2 jun. 2017.

CABREIRA, Adriana Ferreira. Serviços de informação das bibliotecas públicas municipais da grande Florianópolis, 2011. 35f. Trabalho de Conclusão de Curso (Graduação em Biblioteconomia) - Centro de Ciências da Educação, Universidade Federal de Santa Catarina, Florianópolis, 2011. Disponível em:

<https://core.ac.uk/download/pdf/30398694.p df>. Acesso em: 13 nov. 2017.

CAMPELLO, Bernadete Santos. Fontes de informação utilitária em bibliotecas públicas. Revista de Biblioteconomia de Brasília, Brasília, DF, v. 22, n. 1, p. 35-46, 1998.

Disponível em:

<http://basessibi.c3sl.ufpr.br/brapci/v/a/4673

>. Acesso em: 15 maio 2017.

CAMPOS, Luiz Fernando de Barros. Web 2.0, biblioteca 2.0 e ciência da informação: um protótipo para disseminação seletiva de informação na Web utilizando mashups e feeds RSS. In: ENCONTRO NACIONAL DE PESQUISA EM CIÊNCIA DA INFORMAÇÃO, 8., 2007, Salvador. Anais eletrônicos... Disponível em: <http://www.enancib.ppgci.ufba.br/artigos/G T2--232.pdf>. Acesso em: 02 jun. 2017.

CAREGNATO, Sônia Elisa. O desenvolvimento de habilidades informacionais: o papel das bibliotecas universitárias no contexto da informação digital em rede. Revista de Biblioteconomia \& Comunicação, Porto Alegre, v.8, p. 47-55, jan./dez. 2000. Disponível em: <http://eprints.rclis.org/11663/1/artigoRBC.p df $>$. Acesso em: 3 jun. 2017.

CARVALHO, Lidiane dos Santos; LUCAS, Elaine R. de Oliveira. Serviço de referência e informação: do tradicional ao on-line. In: ENCONTRO NACIONAL DE ENSINO E PESQUISA EM INFORMAÇÃO, 6., 2005, 
Salvador. Anais... Salvador: UFBA, 2005.

Disponível em: <http://www.cinformanteriores.ufba.br/vi_anais/docs/LidianeElain eServicoReferencia.pdf >. Acesso em: 9 jun. 2017.

CHIARINI, Tulio; VIEIRA, Karina Pereira; ZORZIN, Paola la Guardia. Universidades federais mineiras: análise da produção de pesquisa científica e conhecimento no contexto do sistema mineiro de inovação.

Nova Economia, Belo Horizonte, v. 22, n. 2, p. 308-332, maio/ago. 2012. Disponível em: <http://www.scielo.br/pdf/neco/v22n2/v22n2 a04.pdf>. Acesso em: 05 jun. 2017.

CUNHA, Murilo Bastos da; CAVALCANTI, Cordelia Robalinho. Dicionário de biblioteconomia e arquivologia. Brasília: Briquet de Lemos, 2008.

DHOLAKIA, Nikhilesh; MUNDORF, Norbert; DHOLAKIA, Ruby Roy. Novos serviços de informação e comunicação: um quadro de referência estratégico. Ciência da Informação [Online]. Brasília, DF, v.26, n.3, 1997. Disponível em: $<$ http://dx.doi.org/10.1590/S010019651997000300002>. Acesso em 12 maio 2017.

FOSKETT, Douglas Jonh. Serviços de informação em bibliotecas. São Paulo: Polígono, 1969.

LANCASTER, Frederick Wilfrid. Pautas para la Evaluación de Sistemas y Servicios de Información. Paris: UNESCO, 1978.

Disponível em:

<http://unesdoc.unesco.org/images/0002/000 299/029962sb.pdf>. Acesso em: 3 jun. 2017.

MACHADO, Frederico Borges; SUAIDEN, Emir José. O papel da biblioteca pública e seus desafios frente aos avanços tecnológicos. In: CONGRESSO BRASILEIRO DE BIBLIOTECONOMIA, DOCUMENTAÇÃO E CIÊNCIA DA INFORMAÇÃO, 25., 2013, Florianópolis. Anais eletrônicos...

Florianópolis: FEBAB, 2013. Disponível em: $<$ https://portal.febab.org.br/anais/article/view/ 1284>. Acesso em: 2 jun. 2017.
MARCONDES, Carlos Henrique; MENDONÇA, Marilia A.; CARVALHO, Suzana M. Serviços via Web em bibliotecas universitárias brasileiras. Perspectivas em Ciência da Informação, Belo Horizonte, v.11 n.2, p. 174 -186, maio/ago. 2006. Disponível em: $<$ http://www.scielo.br/pdf/pci/v11n2/v11n2a0 3.pdf>. Acesso em: 9 jun. 2016.

MENEZES, Estera Muszkat. Pesquisa Bibliográfica. Florianópolis:

CIN/CED/UFSC, 2009.

MERLO VEGA, José Antonio. El Servicio Bibliotecario de Referencia. Anales de

Documentación, Salamanca, v.3, p.93-126, 2000. Disponível em:

<http://revistas.um.es/analesdoc/article/view/ 2471>. Acesso em: 10 nov. 2017.

MORIGI, Valdir José; PAVAN, Cleusa. Tecnologias de informação e comunicação: novas sociabilidades nas bibliotecas universitárias. Ciência da Informação, Brasília, v. 33, n. 1, p. 117-125, jan./abril 2004. Disponível em: <http://www.scielo.br/pdf/ci/v33n1/v33n1a14 .pdf/>. Acesso em: 3 jun. 2017.

POTY, Edigar Pires et al. O uso de novas tecnologias aplicadas a biblioteca universitária: um estudo de caso. In: ENCONTRO REGIONAL DE ESTUDANTES DE BIBLIOTECONOMIA, DOCUMENTAÇÃO, CIÊNCIA DA INFORMAÇÃO E GESTÃO DA INFORMAÇÃO, 14., 2011, São Luis. Anais... Teresina: RABCI, 2011. Não paginado. Disponível em: <http://rabci.org/rabci/sites/default/files/O\%2 0USO \%20DE\%20NOVAS\%20TECNOLOG IAS\%20APLICADAS\%20A\%20 BIBLIOTECA\%20UNIVERSIT\%C3\%81RI A\%20um\%20estudo\%20de\%20caso.pdf>. Acesso em: 03 jun. 2017.

ROZADOS, Helen Beatriz Frota. A informação científica e tecnológica e os serviços de informação. Informação \& Sociedade: Estudos, João Pessoa, v.16, n.1, p.49-62, jan./jun. 2006. Disponível em: $<$ http://www.ies.ufpb.br/ojs/index.php/ies/arti cle/view/441>. Aceso em: 14 maio 2017. 
SEVERINO, Antônio Joaquim. Metodologia do trabalho científico. 23. ed. rev. e atual. São Paulo: Cortez, 2007.

SOARES, Edvaldo. Metodologia científica: lógica, epistemologia e normas. São Paulo: Atlas, 2003.

SOUSA, Margarida Maria de; FUJINO, Asa. A Biblioteca Universitária como ambiente de aprendizagem no ensino superior: desafios e perspectivas. In: ENCONTRO NACIONAL DE PESQUISA EM CIÊNCIA DA INFORMAÇÃO, 10., 2009, João Pessoa. Anais... Rio de Janeiro: ANCIB, 2009. p.
1780-1798. Disponível em:

$<$ http://enancib.ibict.br/index.php/enancib/xe nancib/paper/viewFile/3278/2404>. Acesso em: 3 jun. 2017.

TRZECIAK, Dorzeli Salete. Modelo de observatório para arranjos produtivos locais. 2009. $234 \mathrm{f}$. Tese (Doutorado em Engenharia de Produção) - Programa de PósGraduação em Engenharia de Produção, Universidade Federal de Santa Catarina, Florianópolis, 2009. Disponível em: $<$ https://repositorio.ufsc.br/xmlui/handle/123 456789/92679>. Acesso em: 13 maio 2017. 